\title{
Clorilene, su hijo Segismundo y otros príncipes y princesas polacos en el teatro áureo español en torno al año 1634: Pedro Calderón de la Barca, Antonio Coello, Francisco de Rojas Zorrilla con Lope de Vega al fondo \\ Clorilene, her son Segismundo and other Polish Princes and Princesses in the Spanish Golden Age Theater at 1634: Pedro Calderón de la Barca, Antonio Coello, Francisco de Rojas Zorrilla with Lope de Vega in the Background
}

\section{Beata Baczyńska}

https://orcid.org/0000-0003-2777-8376

Uniwersytet Wrocławski

POLONIA

beata.baczynska@uwr.edu.pl

[Hipogrifo, (issn: 2328-1308), 9.1, 2021, pp. 467-485]

Recibido: 27-02-2021 / Aceptado: 18-05-2021

DOl: http://dx.doi.org/10.13035/H.2021.09.01.28

Resumen. Se estudia el contexto de dos «comedias polacas» escritas en torno a 1634 -No hay ser padre siendo rey de Rojas Zorrilla y Yerros de Naturaleza y aciertos de la Fortuna de Calderón y Coello- , poniendo en tela de juicio, por un lado, la relación intertextual con dos obras maestras anteriores: La vida es sueño de Calderón (primera redacción 1627-1630) y El castigo sin venganza de Lope de 
Vega (1631) y, por otro, su posible implicación con la política de la corte española después de que Ladislao IV Vasa fue elegido (1632) y coronado, a principios de 1633, rey de Polonia. Se ponderan las condiciones de recepción de las comedias y/o tragedias palatinas, cuyo núcleo son los problemas sucesorios, en el contexto cortesano, con una particular atención hacia sus regias espectadoras.

Palabras clave. Lope de Vega; Calderón; Coello; Rojas Zorrilla; Polonia; España; Casa de Austria; Vasa.

Abstract. The article studies the context of two comedias polacas written around 1634: No hay ser padre siendo rey by Rojas Zorrilla and Yerros de Naturaleza y los aciertos de la Fortuna by Calderón and Coello. Their intertextual relations with La vida es sueño (1627-1630) and El castigo sin venganza by Lope de Vega (1631) are presented as well as their possible involvement in the politics of the Spanish court after Ladislaus IV Vasa was elected (1632) and crowned King of Poland at the beginning of 1633. The reception of comedia/tragedia palatina with the succession problems at its core is discussed in the courtly context, with particular attention to the female royal audience.

Keywords. Lope de Vega; Calderón; Coello; Rojas Zorrilla; Polonia; Spain; Casa de Austria; Vasa.

«Mal, Polonia, recibes / a un extranjero, pues con sangre escribes / su entrada en tus arenas» (vv. 17-19). Así es como Rosaura concretiza su «geolocalización», informando a los espectadores de que se ha perdido en el monte, ha perdido su montura y, por poco, pierde la vida. La afectación del soliloquio transmite la determinación de una mujer que, al ignorar su origen y su destino, está dispuesta a cabalgar - «en hábito de hombre de camino»-incluso un «hipogrifo violento» (v. 1). La corte polaca la va a conocer como una dama con el nombre de Astrea. La vida es sueño genera infinitas constelaciones de mensajes y sentidos, también ocultos. El hombre del barroco europeo -el joven Pedro Calderón de la Barca lo era en extremo- sabía que en el mundo real (cuyo espejo es el teatro) no somos capaces de calar todo el misterio de la creación ${ }^{1}$.

De niño, Calderón pudo haber oído hablar de Juana Dantisco, cuyo padre, Juan Dantisco había venido desde la lejana Polonia a la corte española de Carlos V como embajador del rey de Polonia, Segismundo I Jaguellón. Al volver a su patria, el embajador dejó abandonadas en España a su hija y a la madre de esta: como Clotaldo a Rosaura, en Moscovia... En 1596 Doña Juana Dantisco, ya por entonces «viuda del secretario Diego Gracián», fue madrina de Diego, el mayor de los hermanos Calderón². Tuvo que ser una mujer extraordinaria: santa Teresa de 
Jesús la quería y apreciaba mucho. La prole de doña Juana, los Gracián Dantisco - carmelitas, humanistas, escritores, censores ${ }^{3}$ - forman una densa red social y literaria en la España de finales del siglo XVI y principios del XVII.

Son numerosos los trabajos que estudian el contexto de la Polonia calderoniana en La vida es sueño ${ }^{4}$. Mi propósito es revisar las circunstancias históricas (y teatrales) de otras dos comedias áureas con príncipes polacos y princesas polacas fechadas en torno a 1634: No hay ser padre siendo rey de Rojas Zorrilla y Yerros de Naturaleza y aciertos de la Fortuna de Calderón y Coello. Los recientes trabajos de historiadores polacos y españoles permiten conocer cada vez mejor el alcance de las mutuas relaciones entre Polonia y España a lo largo del siglo XVII ${ }^{5}$. Su discreto reflejo es patente, tanto en las obras dramáticas de los poetas españoles, como en la novela bizantina. Un claro repunte se produjo en torno al año 1629, fecha de la publicación de Eustorgio y Clorilene. Historia moscovica por Enrique Suárez de Figueroa y Mendoza. Los nombres de sus protagonistas aparecen en el árbol genealógico del Segismundo calderoniano. Ese mismo año, salió a la luz otra novela, Historia de las fortunas de Semprilis y Genorodano de Juan Enríquez de Mendoza, con un papel destacado de Kasimiro, rey de Polonia ${ }^{6}$. La «primera versión» de La vida es sueño fue escrita entonces, entre 1627 y 1630. La aprobación de Eustorgio y Clorilene data de enero de 1628. El título de la novela pudo haber llegado a los oídos de Calderón mucho antes de que saliera impresa?

\section{LA POLÍTICA: LAS ALIANZAS DE FAMILIA}

La familia Vasa de Varsovia y los Habsburgo de Madrid estaban emparentados. La reina Margarita de Austria (1584-1611), madre de Felipe IV, era hermana de las dos esposas de Segismundo III Vasa: Anna (1573-1598) y Constancia (1588-1631). En mayo de 1624, Ladislao Segismundo Vasa (1595-1648), hijo primogénito del rey de Polonia y Suecia, pudo por fin partir para realizar su grand tour por Europa. Aunque viajaba de incógnito, lo hizo visitando a su amplia y distinguida parentela en Viena, Flandes e Italia. Su estancia en el sitio de Breda, entre los soldados españoles, la documentó Calderón en la comedia fechada en torno a 1625-1627: El sitio de Bredá9.

Polonia -mientras la Guerra de los Treinta Años se iba extendiendo por el continente europeo- se volvió el punto de mira de la diplomacia española ${ }^{10}$. El condeduque Olivares esperaba comprometer a Segismundo III Vasa en su plan político. Al

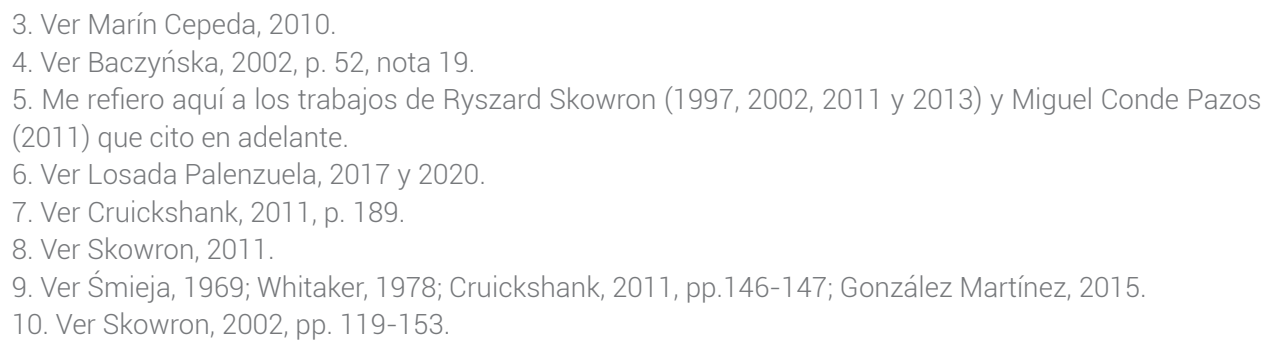


final del año 1625, el rey de Polonia se mostró dispuesto a entrar en la liga católica esperando a cambio ayuda en la guerra contra los suecos para poder recuperar el trono de Suecia. Mikołaj Wolski, su enviado secreto, se reunió en enero de 1626, en Viena, con el embajador de España, Francisco de Moncada, marqués de Aytona. El Consejo de Estado estudió su informe («El papel que dio el Gran Mariscal de Polonia») el 28 de febrero de 1626, cuando el flamenco Jean de Croy, conde de Solre, ya estaba camino a Varsovia para «negociar la adquisición de embarcaciones con las que formar una escuadra española en el Báltico» ${ }^{11}$.

Los diplomáticos españoles solían referirse en sus informes a las tensas relaciones entre el rey Segismundo y su primogénito Ladislao. Rafael Ródenas Vilar, en su libro La política europea de España durante la Guerra de Treinta Años (16241630), observó que el príncipe Ladislao, ya en la primavera de 1627, era «pieza esencial del juego nórdico de la Monarquía española» y que precisaba «de la ayuda y protección españolas para hacer prosperar en candidatura a la Corona polaca» ${ }^{2}$. Me referí a esta cita en 2002, en un artículo dedicado a Polonia y el mar en relación al verso 1430 de La vida es sueño ${ }^{13}$. Aquel año, Ryszard Skowron, historiador polaco, sacó a luz una brillante monografía titulada en polaco Olivares, los Vasas y el Báltico. Polonia en la política exterior de España en los años 1621-163214, así que - con más fundamento- pude escribir en 2005:

La capital de la Polonia calderoniana es una ciudad marítima. Su localización ha sorprendido a más de un calderonista, pues raras veces un hispanista no polaco ha oído hablar de la guerra por el dominium maris Baltici, desarrollada durante casi todo el siglo XVII, y tampoco de la convocación en Madrid, en 1626, del consejo especial para coordinar la totalidad de las acciones relativas al Báltico, es decir, los planes de creación de una flota hispano-polaca, la cual, bajo el mando del príncipe heredero Ladislao, consiguiera el dominio del cuenco del Báltico para los Habsburgo y sus aliados. En el drama de Calderón, Polonia es, desde luego, un país de la ficción y la utopía, lo cual, no obstante, no impide buscar relaciones entre la imaginación del poeta y la realidad histórica, reconociendo su inusitada intuición y perspicacia a la hora de valorar los hechos, y no solo los dramáticos: las investigaciones recientes de los estudiosos de las relaciones hispano-polacas durante la Guerra de los Treinta Años parecen corroborar indirectamente su excepcional sentido de analista político ${ }^{15}$.

\section{EL TEATRO: «DECIR SIN DECIR»}

Muchos de los calderonistas hemos reparado en el acierto de poner La vida es sueño a la cabeza de la Primera parte: Calderón no solo reconoció el drama del príncipe polaco Segismundo como representativo para su obra, sino que se esmeró

11. Elliott, 1990, p. 278.

12. Ródenas Vilar, 1967, p. 114.

13. Baczyńska, 2002.

14. Skowron, 2002

15. Baczyńska, 2016 [2005], p. 401. 
en revisar la comedia antes de sacarla impresa ${ }^{16}$. Frederick A. de Armas, en 2009, volvió a La vida es sueño para insistir otra vez en la complejidad del proyecto teatral calderoniano: «Todas [las] claves astro-mitológicas pueden contener un "decir sin decir"»17. Recalcó que el término hipogrifo habría que tratarlo como «paradójicamente [...] un signo que declara una nueva estética» en oposición al arte de Lope de $V_{\text {ega }}{ }^{18}$. De Armas ya antes había planteado que La vida es sueño se ofrecía como una especie de «mythical agon between Jupiter and Saturn» ${ }^{19}$ : una imagen poética de la confrontación del joven poeta con Lope. En 2005, discrepé: «no creo que el conflicto dramático de La vida es sueño, basado en aquel arquetipo, permita sacar conclusiones interpretativas tan complejas» ${ }^{20}$.

Hoy, al principio del año 2021, no puedo pasar por alto el reciente descubrimiento de la suelta que lleva por título este largo epígrafe Un castigo sin venganza. Que es cuando Lope quiere. Comedia famosa, y que posiblemente es la prínceps de la tragedia «escrita al estilo español» por el Fénix ${ }^{21}$. El impreso vuelve a arrojar luz sobre la relación entre el viejo Lope y el joven Calderón, y el juego intertextual entre El castigo sin venganza y La vida es sueño. Estoy de acuerdo con Alejandro GarcíaReidy en que la intención del Fénix era entrar en diálogo «con ciertos dramas escritos en años recientes, que articulaban [...] coordenadas de tragedia y honor en torno a la idea de venganza» ${ }^{22}$. Es de sumo interés que Lope aluda directamente a La vida es sueño:

FEDERICO Bien dicen que nuestra vida es sueño, y que toda es sueño, pues que no sólo dormidos, pero aun estando despiertos, cosas imagina un hombre que al más abrasado enfermo con frenesí no pudieran llegar a su entendimiento

BATín Dices bien; que alguna vez entre muchos caballeros suelo estar, y sin querer se me viene al pensamiento dar un bofetón a uno, u mordelle del pescuezo. Si estoy en algún balcón, estoy pensando y temiendo echarme dél, y matarme. [...]

16. Ver Ruano de la Haza, 1992b; Vega García-Luengos, Cruickshank y Ruano de la Haza, 2000.

17. De Armas, 2009, p. 92.

18. De Armas, 2009, p. 79; ver De Armas, 1993 y 1998.

19. De Armas, 1993, p. 5.

20. Baczyńska, 2016 [2005], p. 313.

21. García-Reidy, Valdés Gázquez y Vega García-Luengos, 2021.

22. En García-Reidy, Valdés Gázquez y Vega García-Luengos, 2021, p. 272. 


$\begin{array}{ll}\text { FEDERICO } & \text { (¡Jesús! ¡Dios me valga! ¡Afuera, } \\ & \text { desatinados conceptos } \\ & \text { de sueños despiertos! Yo } \\ & \text { ¿tal imagino, tal pienso, } \\ & \text { tal me prometo, tal digo, } \\ & \text { tal fabrico, tal emprendo? } \\ & \text { ¡No más, estraña locura!) (vv. 928-964). }\end{array}$

Lope no se limita a citar la metáfora del título, sino que a continuación, en la intervención de Batín, evoca la situación escénica de la segunda jornada de La vida es sueño con un Segismundo que maltrata a los criados y con «algún balcón» por donde caer y matarse ${ }^{23}$. También en la intervención de Federico se escucha un eco calderoniano: la serie de exclamaciones y preguntas imita el soliloquio de Segismundo cuando asombrado se despierta en el palacio.

Para concluir recordaré - con García-Reidy - que «[e]l 6 de septiembre de 1635, diez días después de la muerte de Lope de Vega, se representó en palacio ante Felipe IV El castigo sin venganza»: «Esta puesta en escena particular quizá fue un pequeño homenaje al más célebre dramaturgo español de su época. La elección de esta tragedia para un tributo póstumo no sería casual: era una obra relativamente reciente $y$, sobre todo, de una calidad indiscutible» ${ }^{24}$.

\section{NO HAY SER PADRE SIENDO REY DE FRANCISCO DE ROJAS ZORRILLA (¿1634?)}

El 1 de enero de 1635, los regios espectadores «Oyeron» No hay ser padre siendo rey, compuesta por Francisco de Rojas Zorrilla, que representó la compañía de Antonio de Prado ${ }^{25}$. El protagonista era Rey de Polonia, sin más. Rojas Zorrilla refundió La piedad en la justicia de Guillén de Castro. Enrico Di Pastena, editor de la comedia de Rojas, observa como «poco explicable el cambio de ambientación», ya que «Castro sitúa la acción en Hungría, Rojas en Polonia» ${ }^{26}$. Es verdad que «el alejamiento en el espacio era convencional para el teatro de la época», pero trasladar la acción de Hungría a Polonia no podía haber sido fortuito en un dramaturgo que comenzaba «su andadura en Palacio, después de haberse ganado el aplauso del público de los corrales» ${ }^{27}$. Di Pastena concluye:

El propio entorno cortesano, común a Calderón y Rojas, debió de funcionar como estímulo añadido para la búsqueda de materiales literarios que también permitieran hacerse eco de preocupaciones sociopolíticas, nada ajenas al código teatral de la época, sobre todo si la entendemos en su estrecha relación con la sustancia ética de los comportamientos representados 28 .

23. Ver Baczyńska, 2016 [2005], pp. 177-178.

24. García-Reidy, Valdés Gázquez y Vega García-Luengos, 2021, p. 272.

25. Cotarelo y Mori, 1911, p. 39.

26. En Rojas Zorrilla, No hay ser padre siendo rey, p. 149

27. En Rojas Zorrilla, No hay ser padre siendo rey, pp. 147 y 149

28. En Rojas Zorrilla, No hay ser padre siendo rey, p. 153. 
Di Pastena enumera afinidades de No hay ser padre siendo rey con La vida es sueño ${ }^{29}$. En otra nota, pondera unos interesantes puntos de contacto con la «tragedia» de Lope que tendrían que llamar la atención de los aficionados del teatro:

[...] asoma en No hay ser padre siendo rey alguna analogía en la onomástica (reaparecen los nombres de Casandra y de Federico -conde en la tragedia de Lope, duque y consejero en la de Rojas), así como algún leve parecido entre el enamoramiento de Rugero al presenciar el baño de Casandra en un curso de agua y el primer encuentro de Federico y Casandra (mientras esta vadea un río con los pies desnudos) $)^{30}$.

En El castigo sin venganza, son dos los homicidios (el de Casandra y de su hijastro y amante, Federico) frente a uno en la comedia de Rojas: Alejandro, hijo segundo del Rey de Polonia, es acuchillado por su hermano Rugero, quien cree dar muerte al duque Federico porque supone que él es el amante de Casandra. El involuntario fratricida es condenado a muerte, pero lo salva el pueblo (polaco) al derrocar al rey dispuesto a castigar con la muerte al único heredero de la corona. Rojas Zorrilla - para emparentar su comedia con la tragedia de Lope y La vida es sueño de Calderón- juega con la materia literaria, al igual que pretende despertar la sensibilidad y la memoria de quienes - como el rey Felipe IV y su corte - tenían el teatro por su habitual pasatiempo.

Polonia es accesorio en No hay ser padre siendo rey. El topónimo aparece solo cuatro veces a lo largo de la comedia: dos veces en la primera jornada, en la escena entre el Rey de Polonia y Rugero (la exposición de la trama); y dos veces en el soliloquio de Casandra, esposa secreta del asesinado, cuando reclama al Rey de Polonia:

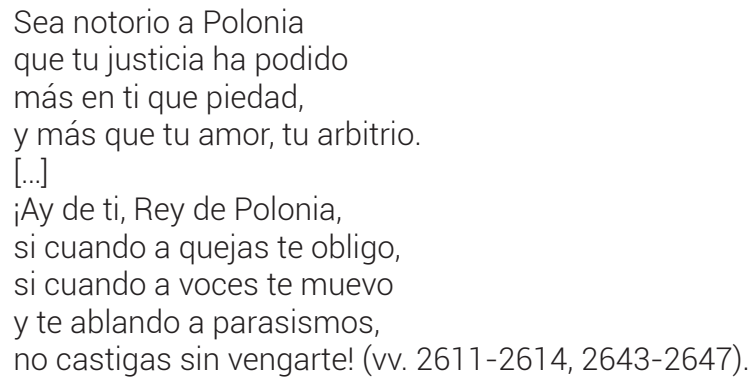

No creo casual que Casandra aluda a El castigo sin venganza justo cuando la trama llega al clímax en su pasional y doloroso monólogo, cuando descubre ante el rey $-y$ a la vez el padre - y ante el mismo asesino que ha sido testigo del fratricidio, y pide castigo y venganza por la muerte del príncipe Alejandro, su esposo. Rojas Zorrilla es muy puntual en cumplir de manera fatal el aviso de la exposición; primero la admonición del padre: 


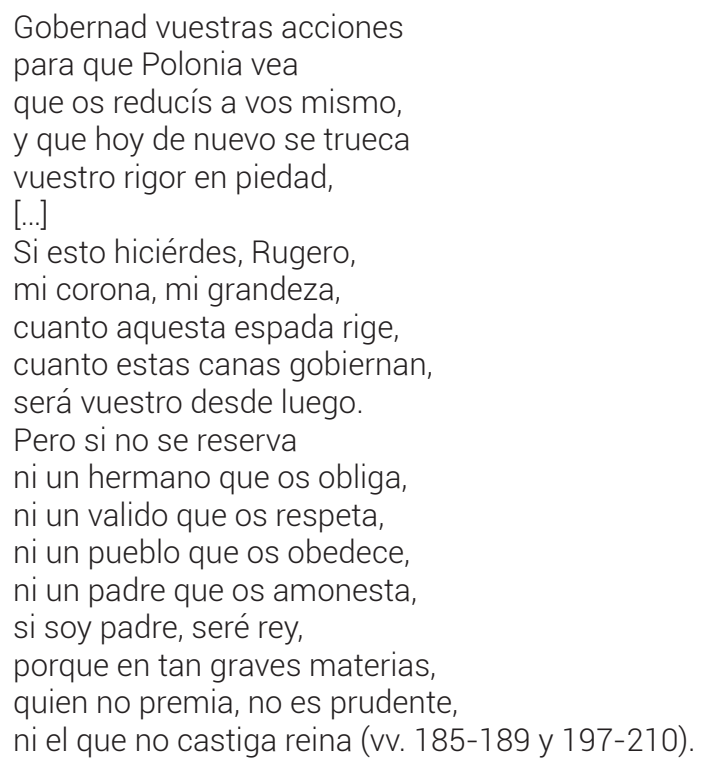

Rojas Zorrilla quiso que el topónimo Polonia resonara también en la violenta respuesta del hijo que se cree «malquisto» (v. 177) y -en cuanto primogénito- no piensa renunciar su legítimo derecho a la corona:

De hoy más, guárdese Polonia;

y mi hermano de tu solio,

de tu palacio real

no mueva los pies medrosos,

que de sus venas mi acero

ha de sacar valeroso,

si el cielo no le sepulta,

sangre que despida en golfos (vv. 365-372).

En la misma jornada Alejandro le cuenta a Casandra su sueño: se trata de una variación sobre el topos somnium vitae en un claro diálogo intertextual con La vida es sueño:

Duérmome... No me dormí, porque el sueño es un ensayo de cada día en que todos la muerte representamos, [...]

Sueño, pues, que, mal herido del acero de mi hermano, anegaba mis suspiros entre mi sangre y mi llanto. Soñando, la espada empuño y dormido me levanto.

Despierto..., y no desperté, 
$[\ldots]$

que con verme en pie y despierto

dudé por muy grande rato

si era sueño el verme libre

o era verdad lo soñado (vv. 737-740, 743-749 y 753-756).

El sueño de Alejandro anuncia el funesto desenlace que dejaría a Polonia sin heredero, si no fuera por el levantamiento popular:

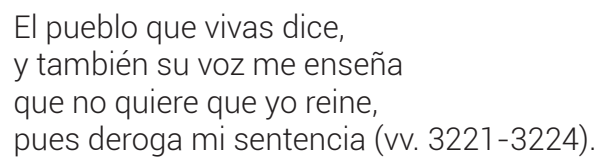

\section{YERROS DE NATURALEZA Y ACIERTOS DE LA FORTUNA DE PEDRO CALDERÓN DE LA BARCA Y ANTONIO COELLO (1634)}

Yerros de Naturaleza y aciertos de la Fortuna, comedia colaborada de Calderón y Coello, es con toda probabilidad anterior a la «comedia polaca» de Rojas Zorrilla. Se conserva el manuscrito, «parcialmente autógrafo», que «[1]leva en su folio 60r la aprobación del censor Jerónimo de Villanueva y la fecha del encargo de esta, el 4 de mayo de 1634, único dato que nos permite fechar el texto», según apunta Erik Coenen en su rigurosa edición ${ }^{31}$. El reparto contempla a Segismundo y Rosaura como personajes secundarios: hijos de Filipo, privado del rey polaco, Manfredo, cuya muerte en las guerras con Moscovia es el desencandente de la trama.

En Yerros es la hermana Matilde quien pretende usurpar la corona que hereda su hermano Polidoro, de acuerdo con la ley que prioriza al varón como sucesor. Tal precepto fue promulgado por el rey Manfredo quien, en su momento, arrebató la corona a Clorilene, la única hija de Conrado, rey de Polonia, su hermano. Segismundo y Rosaura son hijos de Clorilene porque Manfredo se la dio por esposa a «su mayor amigo y deudo, / [...], porque fuese tu lealtad / de sus intenciones freno» (vv. 126-130). Estas palabras forman parte de una relación en romance que Matilde dirige a Filipo, «viudo de la prima de los dos [hermanos] ${ }^{32}$, para confiarle su estratagema de hacerse con el reino de Polonia eliminando a su hermano mellizo. Aprovechando el parecido entre los dos, piensa vestirse con sus trajes para hacerse pasar por Polidoro:

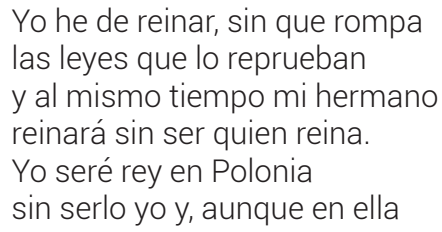

31. En Calderón y Coello, Yerros de Naturaleza y aciertos de la Fortuna, p. 13.

32. Calderón y Coello, Yerros de Naturaleza y aciertos de la Fortuna, p. 45. 
no puede reinar mujer,

habrá rey que mujer sea.

Yo he de morir sin morir.

siendo mi hermano quien gobierne

será sin ser quien gobierna,

y, en fin, morirá mi hermano

cuando más vivir parezca

$y$, al contrario, tendré vida

yo cuando morir me vea (vv. 977-992).

La comedia nunca tuvo buena crítica entre los calderonistas. Cruickshank escribe explícitamente que fue un fracaso ${ }^{33}$. Hasta hace relativamente poco se creía incluso que Yerros de Naturaleza y aciertos de la Fortuna fue anterior a La vida es sueño ${ }^{34}$. Ahora ya no cabe duda de que fue al contrario, y que la obra se compuso pensando en la compañía de Cristóbal de Avendaño y, principalmente, en su «autora», María Candado, que iba a hacer los dos papeles, el de Polidoro y el de su hermana, Matilde ${ }^{35}$.

Los autores de Yerros quisieron que el topónimo Polonia resonara entre el público. La comedia arranca con gritos de aplauso: «iViva Polidoro! ¡Viva / de Polonia el heredero!» (vv. 1-2). A lo largo de la primera jornada la palabra se pronuncia hasta catorce veces; en la segunda dos y en la tercera, seis; los dos últimos en el discurso final de Polidoro:

Corte de Polonia, amigos: bien miráis la providencia con que el cielo me ha guardado, y esta espantosa tragedia bien podéis adivinar el misterio que en sí encierra.

Ambición fue de Matilde que el cielo dejó deshecha, $y$, aunque es verdad que conozco que ella solo no pudiera ser todo en aquesta hazaña y que hay cómplices en ella, nada desto se averigüe; $[\ldots]$ Filipo a mi gracia vuelva, $y$, por soldar el desaire que os hice, Rosaura sea

33. Cruickshank, 2011, p. 189.

34. Ver Sloman, 1958, pp. 250-277; Ruano de la Haza, 1992a.

35. En Calderón y Coello, Yerros de Naturaleza y aciertos de la Fortuna, pp. 18-19; Calderón volvió a plantear el mismo «ingenioso reparto que permitía a una persona interpretar dos papeles» en La hija del aire (Cruickshank, 2011, p. 235). 
hoy mi esposa, y Segismundo, que de Polonia hizo ausencia, vuelva a gobernar mis armas para que con esto [...] (vv. 3102-3115 y 3130-3136).

Erik Coenen observa que la decisión de Polidoro de que «nada de esto se averigüe» permite «la solución [...] de los conflictos pendientes. El rey ha entendido el enigmático mensaje que explica que Matilde ha pagado por su afrenta a Rosaura, Segismundo y Filipo [...], reestableciendo la armonía entre las dos ramas de la dinastía reinante» 36 .

\section{DESENLACES Y ENLACES. A MODO DE CONCLUSIÓN}

Enrico Di Pastena concluye lo mismo en relación a No hay ser padre siendo rey: «el desenlace no deja de ser significativo desde un punto de vista ideológico por el papel que en él desempeña la razón de estado»:

Entre las obligaciones reales, estaba la de someterse a las leyes [...], pero también la de conservar la estabilidad del reino. Al contrario, en su afán de garantizar una aplicación ejemplar de la justicia, el soberano a punto está de dejar Polonia sin cabeza; el necesario ajuste del final preserva la institución monárquica ciñéndose a su mecanismo de sucesión, y con ello garantiza la paz social. No es de extrañar que algunos testimonios del Seiscientos que nos han transmitido el texto, en un pasaje añadido amplifiquen precisamente las nefastas consecuencias sociales que sufriría un país privado de sus herederos legítimos [...] ¿No había escrito Mariana que es [el pueblo] quien confirma la legitimidad del heredero? ${ }^{37}$

Me gustaría llamar la atención sobre otro posible contexto político. Olivares en repetidos memoriales avisaba a Felipe IV «sobre el estado de los señores infantes don Carlos y don Fernando». John H. Elliott escribe:

[...] mientras los infantes siguieran en la corte, la única manera de impedir que se convirtieran en centro de una facción era rodearlos de cortesanos que le fueran leales. El problema no se resolvería hasta 1632, cuando se produjo la muerte repentina de don Carlos a finales de julio, y se envió al cardenal-infante como virrey de Cataluña y luego como gobernador de Flandes ${ }^{38}$.

Los maliciosos achacaron la temprana muerte del infante don Carlos «al veneno administrado por orden del conde-duque, supuestamente celoso de la popularidad que el débil y joven príncipe tenía entre la nobleza disidente» ${ }^{39}$.

36. En Calderón y Coello, Yerros de Naturaleza y aciertos de la Fortuna, p. 159 (nota al v. 3115).

37. En Rojas Zorrilla, No hay ser padre siendo rey, pp. 152-153.

38. Elliott, 1990, p. 417

39. Elliott, 1990, p. 513 
Por otro lado, creo importante observar que a partir de junio de 1632, cuando a Madrid llegó la noticia de la muerte de Segismundo III Vasa, la situación de sus hijos fue un tema constante en la agenda diplomática española. El 26 de diciembre de 1632, el Duque de Feria - quien había conocido al príncipe Ladislao, cuando visitó Milán a finales del año 1624- escribió a Felipe IV:

[...] será de grande importancia que Vuestra Majestad se sirviese de ayudar y asistir este Príncipe en la mejor forma que se pudiese pues no puede haber jamás tan buena ocasión como esta en que solo ha quedado de Gustavo una hija [...]. Las conveniencias de Vuestra Majestad en estas guerras después de ayudar a aquel príncipe de su sangre y tan católico, son grandes porque no sólo moviendo la guerra se retirarán de Alemania las cabezas suecas que hay en ella y luego los presidios y soldados de aquel reino, sino que si Dios se le diese al rey Ladislao sería de grandísimo daño a los holandeses, que tienen comercio muy considerable en el mar Báltico y con aquel reino donde todo el tiempo del rey muerto han sido muy poderosos. Y siempre será de gran conveniencia que el rey de Polonia tenga mayor poder y reputación ${ }^{40}$.

Y, efectivamente, ese era también el plan de Olivares. En la consulta del Consejo de Estado, fechada el 9 de enero de 1633, entre los propósitos inmediatos de la política exterior española referidos por el conde-duque figura explícitamente: «El casamiento del polaco con la hija del sueco» ${ }^{41}$.

La hija del «sueco» se llamaba Cristina y tenía entonces apenas siete años. Desde hacía un año era reina de Suecia (Gustavo II Adolfo Vasa, su padre, perdió la vida en Lützen, aunque sus tropas ganaron la batalla). Ladislao IV Vasa, elegido por la nobleza polaca - tras la muerte de su padre Segismundo III Vasa- fue coronado el 6 de febrero de 1633 a la edad de treinta y siete años ${ }^{42}$. Apenas tres semanas después, el 26 de febrero de 1633, hizo una ceremoniosa entrada en Cracovia la comitiva de don Diego Juan Velasco de la Cueva, conde de Siruela, que contaba con 120 hombres a caballo, según un diarista de la época. El conde de Siruela venía para felicitar a Ladislao IV Vasa por su ascenso al trono en nombre de Felipe IV. EI rey de Polonia le dio audiencia en público el 28 de febrero de 1633, a continuación el conde «visitó a los príncipes y la princesa Anna» ${ }^{43}$.

Los Vasa de Varsovia seguían utilizando el título de la corona sueca y eran católicos. Segismundo III Vasa, coronado en Uppsala en 1594 como rey de Suecia, cinco años después, en 1599, fue derrocado a raíz del levantamiento de la nobleza sueca, en su gran mayoría luterana, encabezado por su tío (y regente) el duque Carlos de Södermanland: Carlos IX de Suecia fue padre de Gustavo II Adolfo y abuelo de Cristina de Suecia. El árbol genealógico de Yerros parece reflejar las complejas relaciones entre las dos ramas de la dinastía de los Vasa, la polaca y la sueca.

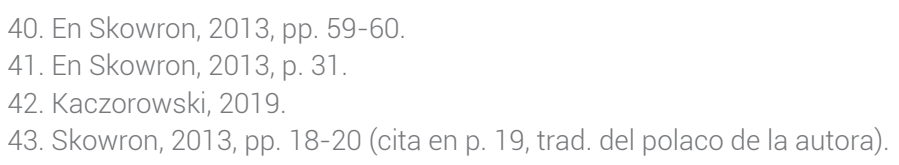


Por otro lado, el ambiente de complot encubierto corresponde de una manera indirecta con las circunstancias de la violenta y vil muerte de Wallenstein. Cuando el 26 de marzo de 1634 la noticia de que «había sido hallado culpable de alta traición al Emperador y había sido asesinado en Eger el día 25 de febrero por los oficiales a su mando» tomó por sorpresa al conde-duque Olivares ${ }^{44}$. Es más, Calderón y Coello le habían dedicado al famoso duque de Friedland una comedia, según se desprende de «una carta del embajador de Florencia, Serrano, con fecha de 4 de marzo». En palabras de Germán Vega García-Luengos: «la explicación más plausible de la razón de ser y de las características de la comedia perdida estriba en asociarla al entorno de Olivares y sus intereses, y considerarla como una baza dentro de esa política de emergencia» ${ }^{45}$.

Las dos «comedias polacas», tanto la colaborada de Calderón y Coello, como No hay ser padre siendo rey de Rojas Zorrilla, se inscriben en las coordenadas políticas de aquel fatídico suceso, aunque tanto la fabulosa topografía de Polonia como los nombres de los protagonistas permiten marcar una decorosa distancia hacia los «príncipes vivientes». En 1634 Ladislao IV Vasa, rey de Polonia, seguía siendo soltero, asimismo sus cinco medio hermanos, cuatro príncipes y una princesa ${ }^{46}$. El más joven de los Vasa, Aleksander Karol (Alejandro Carlos), en 1634 pretendía llegar a Madrid en busca de su fortuna ${ }^{47}$. La corte madrileña esquivó el compromiso (¿cabría la posibilidad que el príncipe Alejandro de la comedia de Rojas Zorrilla «aludiera sin aludir» a aquel huésped indeseado48?). Sin embargo, su estancia en Milán y el recibimiento por el cardenal-infante don Fernando fueron documentados en detalle por Diego de Aedo y Gallarte:

A los fines de marzo llegó a Milán el hermano del Rey de Polonia llamado Ladislao, primo hermano de Su Alteza a quien hospedó magníficamente en Palacio y comieron algunas veces juntos; estuvo doce días y Su Alteza le presentó seis caballos con ricos aderezos y otras cosas curiosas y de valor ${ }^{49}$.

Ladislao IV Vasa, por su parte, el 10 de junio de 1634 se adelantó a informar a Felipe IV de la inminente firma del Tratado de Paz con el Ducado de Moscovia ${ }^{50}$. En Madrid ya antes circulaba la Relación verdadera de la insigne victoria que alcanzó Rey de Polonia contra el gran duque de Moscovia y otros confederados suyos, todos enemigos de nuestra santa fe y de las coronas de la casa de Austria, enviada del ejército de su majestad de Polonia, su fecha en 24 de marzo de 1634. En 1635 vencía la tregua entre Polonia y Suecia. La firma de la paz perpetua con Mosco-

44. Elliott, 1990, p. 463.

45. Vega García-Luengos, 2001, p. 796,

46. Con fecha del 17 de junio de 1634 el embajador del rey de Polonia presentó en Madrid el «Memorial sobre las partes de los cuatro Príncipes y Princesa, hermanos de aquel Rey» abogando que «ahora todos estos Serenísimos Príncipes no poseen todo lo que conviene a su grandeza y nacimiento»; cito por Skowron, 2013, pp. 50 y 51

47. Skowron, 2013, p. 41.

48. Skowron, 2013, pp. 40-46.

49. En Skowron, 2013, p. 46.

50. Tratado de Poliánovka fue firmado el 14 de junio de 1634 
via permitía a Varsovia plantearse la guerra con Suecia. Ladislao IV Vasa sondeaba a sus aliados. La victoria de Nördlingen, en septiembre de 1634, iba a precipitar los acontecimientos complicando los futuros enlaces: «la guerra con Francia era inevitable» ${ }^{51}$.

El 9 de agosto de 1637 Cecilia Renata, hija del emperador Fernando II y hermana de su sucesor Fernando III, contrajo matrimonio per procura con Ladislao IV Vasa. Al rey de Polonia lo representaba su medio hermano Juan Casimiro quien, al año siguiente, sería protagonista de un singular suceso: «el encierro por parte de los franceses [...] cuando se dirigía hacia España» donde esperaba ser nombrado Virrey de Portugal, pero «le sirvió de rehén a Richelieu, quien planteó utilizarlo para forzar a los Vasa a que se alejaran de los Habsburgo»52. Un posible lance de comedia, y no era la última aventura política del medio hermano de rey de Polonia. Por cierto, Estebanillo González -en cuanto correo del Emperador - visitó dos veces la corte polaca. Por un explícito encargo del archiduque Leopoldo Guillermo Habsburgo, le trajo a Cecilia Renata «unas puntas y una muñeca vestida al traje francés, para que sus sastres tomasen el modelo y le hiciesen de vestir a uso de aquel reino, por ser el de Polonia embarazado y no a su gusto» ${ }^{53}$. Resulta conmovedora la implicación del archiduque, hermano menor de la reina de Polonia, que complacía el interés de la joven reina de Polonia por la moda actual con un maniquí vestido a la francesa traído de Bruselas. Al año siguiente, el 24 de marzo de 1644, la reina falleció debido a una infección posparto al dar luz a una hija muerta. Nada más llegar la triste noticia a Madrid, Isabel de Borbón ${ }^{54}$-en nombre de Felipe IV que estaba entonces aun en Cataluña- mandó celebrar en las Descalzas Reales Honras [...] por S. M. la Reina de Polonia y Suecia, Hermana del Emperador de Austria Fernando III, en 77 y 18 de junio de $7644^{55}$. A la semana siguiente se reunió el Consejo de Estado para decidir quién -en nombre del rey de España- iría a Varsovia para darle las condolencias al rey de Polonia por la muerte de Cecilia Renata y hablarle de la nueva candidata para esposa.

Sin embargo, esa vez la actividad de los diplomáticos de la corte española ya no pudo evitar que el rey polaco se comprometiera con los franceses ${ }^{56}$. Ladislao IV Vasa se casó en 1646, en segundas nupcias, con la princesa María Luisa de Gonzaga-Nevers. Murió dos años más tarde. La dieta electiva eligió al príncipe Juan

51. Skowron, 2013, p. 68

52. Conde Pazos, 2011, pp. 123 y 128; ver también Skowron, 2013, pp. 201-250.

53. La vida y hechos de Estebanillo González, vol. I, pp. 201-202; ver Piłat Zuzankiewicz, 2012.

54. La reina de España, Isabel de Borbón, moriría apenas un medio año más tarde; cito de la entrada biográfica de la RAH: «en la primavera de 1644, tuvo un aborto. Era el quinto que sufría y tardó varios meses en reponerse. En el verano reanudó su trabajo administrativo, pero en octubre cayó de nuevo enferma y el día 6 por la mañana murió, con cuarenta y dos años, en medio de una gran discusión entre sus médicos que [...] hicieron tal variedad de diagnósticos que no se podía decir cuál era la causa verdadera del deceso» (Sanz Ayán).

55. Ver Skowron, 2013, pp. 275-287.

56. Skowron, 1997, pp. 183-184; 2013, pp. 271-313. Su posible reflejo teatral lo encontramos en El príncipe perseguido; ver Baczyńska en Belmonte, Moreto y Martínez de Meneses, El príncipe perseguido, p. 17. 
Casimiro, quien tuvo que renunciar al capelo cardenalicio para poder ser coronado y... casarse con la reina viuda. Los enlaces y desenlaces dinásticos se parecían mucho a los lances de comedia seria palatina ${ }^{57}$.

¿Qué tienen en común las «comedias polacas» con El castigo sin venganza de Lope además de la aemulatio lúdica, aquel aliciente añadido de la representaciones particulares (los jueves y los domingos, en palacio), pero también de las públicas, en los corrales ${ }^{58}$ ? Todas se refieren a los problemas sucesorios, un tema de fundamental valor para monarquías hereditarias. Polonia no lo fue. Clorilene, la difunta madre de Segismundo, que fue reina de Polonia en La vida es sueño, y la otra Clorilene, que no llegó a ser reina de Polonia, y fue madre de Rosaura y Segismundo en Yerros de Naturaleza y los aciertos de la Fortuna, simbolizan la difícil suerte de infantas y princesas en aquellos tiempos: obligadas a perpetuar a los Austrias en Madrid y en Viena; a sellar los tratados con su cuerpo al desplazarse a otros reinos para nunca más volver a ver a sus parientes; a correr el riesgo de muerte con cada embarazo y parto ${ }^{59}$, como Clorilene.

Las reinas morían jóvenes (quizá por eso no hay madres en el teatro áureo español). En Madrid, pero también en Viena (e incluso en Varsovia), se las entretenía con las historias de fabulosas heroínas de la comedia española ${ }^{60}$ : Rosaura/Astrea que lucha por ser reconocida por Astolfo, y por conocer a su padre; Casandra, una joven y triste mujer del duque de Ferrara que se enamora del hijo ilegítimo de su esposo; Matilde dispuesta a eliminar a su hermano para disfrutar reinando Polonia. Las comedias y/o tragedias de ambiente palatino se ofrecían sin duda también como un «régimen de príncipes» escénico. En todas llama la atención la independencia de sus protagonistas femeninas. Es también el caso de las «comedias polacas», y -en particular- de Matilde, hija de Rosimunda, en Yerros de Naturaleza y aciertos de la Fortuna, pero también de Casandra capaz de sobreponerse al dolor y pedir clemencia para el asesino de su esposo por ser el fratricida Rugero el único heredero de la corona de Polonia61.

\section{Zugasti, 2015}

58. El mismo Rojas Zorrilla hizo un irónico retrato, anno domini 1637, «de aquellos que Madrid llama "ingenios de la corte", y palacio "vulgares de la villa" que a cada escena que oían leer, decían: "Mío es este paso, aquel estotro es mío y mío estotro, mío este episodio"» (Academia burlesca, p. 227). Ver Baczyńska en Belmonte, Moreto y Martínez de Meneses, El príncipe perseguido, pp. 13-14.

59. Ver Aichinger y Standhartinger, 2020.

60. Baczyńska, 2018

61. Me gustaría terminar con la referencia a una de las espectadoras privilegiadas del repertorio que es objeto de este trabajo, Isabel de Borbón: «No cabe duda de que, si durante la primera parte del matrimonio la relación con doña Isabel no pasó de discreta, durante los últimos años los lazos de respeto, afecto y confianza se estrecharon intensamente hasta convertirse en "la mejor azucena de Francia" -como rezaba en los motes de su túmulo funerario-, en "el mayor tesoro de Felipe IV" y cuyo recuerdo, magnificado en los años inmediatamente posteriores a su desaparición, quedó vinculado a la imagen de la buena gobernante» (Sanz Ayán). 


\section{BiBLIOGRAFÍA}

Academia burlesca que se hizo en Buen Retiro a la Majestad de Filipo Cuarto el Grande. Año 1637, ed. María Teresa Julio, Madrid / Frankfurt am Main, Iberoamericana / Vervuert, 2007.

Aichinger, Wolfram, y Standhartinger, Christian, «Midwife Diplomacy. The Recruitment of a Midwife for Empress Margarita María Teresa de Austria», Memoria y Civilización, 23, 2020, pp. 583-602.

Baczyńska, Beata, «Polonia y el mar: en torno al verso 1430 de La vida es sueño de Pedro Calderón de la Barca», Scriptura, 17, 2002, pp. 47-63.

Baczyńska, Beata, Dramaturg w wielkim teatrze historii. Pedro Calderón de la Barca, Wrocław, Wydawnictwo Uniwersytetu Wrocławskiego, 2005. Versión castellana, corregida y ampliada: Pedro Calderón de la Barca: dramaturgo en el gran teatro de la historia, trad. Justyna C. Nowicka y Beata Baczyńska, rev. Trinidad Marín Villora, Alicante, BVMC, 2016, en línea: http://www.cervantesvirtual. com/nd/ark:/59851/bmck37r2.

Baczyńska, Beata, «Príncipes perseguidos y valientes damas de comedia. El espacio de la Europa del Este y del Norte en el teatro áureo español», en Aspectos actuales del hispanismo mundial: Literatura - Cultura - Lengua, ed. Christoph Strosetzki, Berlín, Walter de Gruyter, 2018, pp. 403-414.

Belmonte, Luis de, Moreto, Agustín, y Martínez de Meneses, Antonio, El príncipe perseguido, ed. Beata Baczyńska, Madrid, BVMC, 2021 (Colección digital PROTEO, 16), en línea <http://www.cervantesvirtual.com/nd/ark:/59851/ bmc1051268>

Calderón de la Barca, Pedro, La vida es sueño, ed. Evangelina Rodríguez Cuadros, Madrid, Espasa Calpe, 1997. Version HTML en línea: <http://www.cervantesvirtual.com/nd/ark:/59851/bmc542n2>.

Calderón de la Barca, Pedro, y Coello, Antonio, Yerros de Naturaleza y aciertos de la Fortuna, ed. Erik Coenen, Kassel, Reichenberger, 2019.

Conde Pazos, Miguel, «El tratado de Nápoles. El encierro del príncipe Juan Casimiro y la leva de polacos de Medina de las Torres (1638-1642)», Studia historica. Historia moderna, 33, 2011, pp. 123-139.

Cotarelo y Mori, Emilio, Don Francisco de Rojas Zorrilla: noticias biográficas y bibliográficas, Madrid, Imp. de la Revista de Archivos, 1911.

Cruickshank, Don W., Calderón de la Barca. Su carrera secular, trad. José Luis Gil Aristu, Madrid, Gredos, 2011.

De Armas, Frederick A., «The Critical Tower», en The Prince in the Tower. Perceptions of «La vida es sueño», ed. Frederick A. de Armas, Lewisburg, Bucknell University Press, 1993, pp. 3-14. 
De Armas, Frederick A., «The Hippogryph Wars: Lope de Vega, Claramonte and Calderón», en A Society on Stage. Essays on Spanish Golden Age Drama, ed. Edward H. Friedman, H. J. Manzari y Donald D. Mille, New Orleans, University Press of the South, 1998, pp. 45-58.

De Armas, Frederick A., «Papeles de zafiro: signos político-mitológicos en La vida es sueño», Anuario Calderoniano, 2, 2009, pp. 75-96.

Elliott, John H., El conde-duque de Olivares. El político en una época de decadencia, trad. Teófilo de Lozoya, rev. Antonio Feros y el autor, Barcelona, Crítica, 1990.

García-Reidy, Alejandro, Valdés Gázquez, Ramón, y Vega García-Luengos, Germán, «Una nueva edición (¿princeps?) de El castigo sin venganza», Anuario Lope de Vega. Texto, literatura, cultura, XXVII, 2021, pp. 270-329.

González Martínez, Lola, «El tratamiento de la historia contemporánea en El sitio de Bredá, comedia de Calderón», en Tiempo e historia en el teatro del Siglo de Oro. Actas selectas del XVI Congreso Internacional, Aix-en-Provence, Presses Universitaires de Provence, 2015, s. p.; en línea: https://books.openedition. org/pup/4668.

Kaczorowski, Włodzimierz, «Wolna elekcja viritim i koronacja Władysława IV», en Świat polskich Wazów. Eseje, ed. Jacek Żukowski y Zbigniew Hundert, Warszawa, Zamek Królewski w Warszawie, 2019, pp. 219-237.

La vida y hechos de Estebanillo González, hombre de buen gusto. Compuesto por el mesmo, ed. Antonio Carreira y Jesús Antonio Cid, Madrid, Cátedra, 1990.

Losada Palenzuela, José Luis, «Desplazamiento de la imagen septentrional: Polonia en La historia de las fortunas de Semprilis y Genorodano», en Ficciones entre mundos. Nuevas lecturas de «Los trabajos de Persiles y Sigismunda» de Miguel de Cervantes, ed. Jörg Dünne y Hanno Ehrlicher, Kassel, Reichenberger, 2017, pp. 253-273.

Losada Palenzuela, José Luis, «El Reino de Loango: fuentes cartográficas y textuales en Semprilis y Genorodano (1629)», Revista de literatura, vol. 82, núm. 164, 2020, pp. 469-489; en línea: https://doi.org/10.3989/revliteratura.2020.02.018.

Marín Cepeda, Patricia, «Nuevos documentos para la biografía de Tomás Gracián Dantiso, censor de libros y comedias de Lope de Vega (I)», en Cuatrocientos años del «Arte nuevo de hacer comedias» de Lope de Vega. Actas selectas del XIV Congreso de la Asociación Internacional de Teatro Español y Novohispano de los Siglos de Oro. Olmedo, 20 al 23 de julio de 2009, ed. Germán Vega García-Luengos y Héctor Urzáiz Tortajada, Valladolid, Universidad de Valladolid, 2010, vol. 3, pp. 705-714.

Piłat Zuzankiewicz, Marta, «Las aventuras polacas de Estebanillo González a la luz de los relatos diplomáticos y documentos históricos», Itinerarios, 16, 2012, pp. 201-219. 
Ródenas Vilar, Rafael, La política europea de España durante la Guerra de Treinta Años (1624-1630), Madrid, CSIC, 1967.

Rojas Zorrilla, Francisco de, No hay ser padre siendo rey, ed. Enrico Di Pastena, en Obras completas, vol. I, ed. Felipe B. Pedraza Jiménez, Rafael González Cañal y Elena E. Marcello, Cuenca, Ediciones de la Universidad Castilla-La Mancha, 2007, pp. 145-276.

Ruano de la Haza, José María, «En torno a una edición crítica de La vida es sueño de Calderón», Mélanges de la Casa de Velázquez, 28.2, 1992a, pp. 27-40.

Ruano de la Haza, José María, La primera versión de «La vida es sueño» de Calderón, Liverpool, Liverpool University Press, 1992b.

Sanz Ayán, Carmen, «lsabel de Borbón», en Real Academia de la Historia, Diccionario Biográfico electrónico, en línea: http://dbe.rah.es/biografias/13025/isabelde-borbon.

Skowron, Ryszard, Dyplomaci polscy w Hiszpanii w XVI i XVII wieku, Kraków, Universitas, 1997.

Skowron, Ryszard, Olivares, Wazowie i Bałtyk. Polska w polityce zagranicznej Hiszpanii w latach 1621-1632, Kraków, Towarzystwo Wydawnicze "Historia lagellonica", 2002.

Skowron, Ryszard, «Los aliados de las esperanzas fallidas. La Casa de Austria y los Vasa de Polonia (1598-1648)», en La Dinastía de los Austrias. Las relaciones entre la Monarquía Católica y el Imperio, Madrid, Polifemo, 2011, vol. 2, pp. 997-1022.

Skowron, Ryszard, Pax i Mars. Polsko-hiszpańskie relacje polityczne w latach 16321648, Kraków, Uniwersytet Śląski w Katowicach / Towarzystwo Wydawnicze "Historia lagellonica", 2013.

Sliwa, Krzysztof, Cartas, documentos y escrituras de Pedro Calderón de la Barca Henao de la Barrera Riaño (1600-1681) y de sus familiares, fénix de los ingenios y lucero mayor de la poesía española, Valencia, Universitat de València, 2008.

Sloman, Albert E., The Craftsmanship of Calderón. His Use of Earlier Plays, Oxford, Dolphin Book, 1958.

Śmieja, Florian, «El príncipe de Polonia ante Breda, según un diario coetáneo», Revista de Literatura, vol. 35, núms. 69-70, 1969, pp. 95-103.

Vega Carpio, Lope de, El castigo sin venganza, ed. Prolope (PPU), Alicante, BVMC, 2016; en línea: http://www.cervantesvirtual.com/nd/ark:/59851/bmc2r5s1. 
Vega García-Luengos, Germán, «Calderón y la política internacional: las comedias sobre el héroe y traidor Wallenstein», en Calderón de la Barca y la España del Barroco, ed. José Alcalá-Zamora y Queipo de Llano y Ernest Berenguer Cebriá, Madrid, Centro de Estudios Políticos y Constitucionales, 2001, vol. 2, pp. 793-827.

Vega García-Luengos, Germán, Cruickshank, Don W., y Ruano de la Haza, José María, La segunda versión de «La vida es sueño», de Calderón, Liverpool, Liverpool University Press, 2000.

Whitaker, Shirley B., «The First Performance of Calderón's El sitio de Bredá», Renaissance Quarterly, 31.4, 1978, pp. 515-531.

Zugasti, Miguel, «A vueltas con el género de La vida es sueño: comedia palatina seria», Cuadernos de Teatro Clásico, 31, 2015, pp. 257-296. 